\title{
IMPROVING QUALITY OF PREVENTION OF MOTHER-TO-CHILD HIV TRANSMISSION SERVICES IN UKRAINE: A FOCUS ON PROVIDER COMMUNICATION SKILLS AND LINKAGES TO COMMUNITY-BASED NON-GOVERNMENTAL ORGANIZATIONS
}

\author{
Kateryna Gamazina', Iryna Mogilevkina², Zhanna Parkhomenko', Amie Bishop ${ }^{3}$, Patricia S. Coffey ${ }^{3}$, Tracy Brazg ${ }^{3}$ \\ 1PATH, Ukraine Office, Kyiv, Ukraine \\ 2Donetsk National Medical University, Department of Obstetrics, Gynecology and Perinatology, Donetsk, Ukraine \\ ${ }^{3}$ PATH, Seattle, USA
}

\begin{abstract}
SUMMARY
Background: Ukraine has the highest rate of HIV infection in Europe, with an estimated adult prevalence of 1.6 percent. The epidemic in Ukraine remains largely driven by injection drug use, and women of reproductive age are being increasingly affected. Prior research has highlighted the need to improve the quality of services for prevention of mother-to-child transmission (PMTCT) and to address other issues related to HIV counseling, testing, and care, especially in the context of antenatal and obstetric services.

Methods: From 2004 to 2007, PATH led a collaborative effort to improve the quality of PMTCT services in Ukraine. Initial assessments included focus groups with Ukrainian women and review of existing educational materials. Interventions focused on training providers to improve skills in communication and referral to community-based support; they also addressed the underlying issue of stigma.

Results: Observational data demonstrated that providers who participated in the training intervention delivered PMTCT counseling of a consistently higher quality than did providers who did not undergo training. Exit interviews with clients confirmed these findings.

Conclusions: An intervention focused on strengthening voluntary counseling and testing for HIV, forging partnerships with local organizations, and undoing HIV-related stigma can help to improve access to and quality of PMTCT services in antenatal care clinics.
\end{abstract}

Key words: HIVIAIDS stigma, prevention of mother-to-child HIV transmission, voluntary counseling and testing, provider training, Ukraine

Address for correspondence: A. Bishop, PATH, 1455 NW Leary Way, Seattle WA, 98103, USA. E-mail: abishop@path.org

\section{INTRODUCTION}

Ukraine has the highest rate of HIV infection in Europe, with an estimated adult prevalence of 1.6 percent (1). HIV transmission in Ukraine is largely driven by injection drug use $(2,3)$, and women are increasingly affected $(3,4)$. The percentage of new HIV diagnoses among women rose from 24 percent in 1996 to an estimated 44 percent in $2007(5,6)$. The estimated HIV prevalence among pregnant women is 0.5 percent nationwide and greater than 1 percent in some regions $(7,8)$. High-quality interventions for HIV-positive pregnant women as part of Ukraine's overall national HIV strategy are clearly needed.

\section{Background}

In 2001, the Ukrainian Ministry of Health introduced a strategy to integrate prevention of mother-to-child transmission (PMTCT) activities into maternal and child health services. The PMTCT Programme provides free antenatal testing, rapid testing at delivery, and management of HIV-positive women before, during, and after delivery (8). Voluntary counseling and testing (VCT) for pregnant women and their partners is an essential entry point for PMTCT and HIV-related services and theoretically is central to Ukraine's PMTCT Programme. Lack of provider training and stigma, however, have impeded VCT integration. A 2006 Human Rights Watch report found that health care providers in Ukraine widely discriminated against HIV-positive people by turning them away from hospitals, discharging them when their HIV status became known, and providing poor quality of care (9). Research also has highlighted the need for improved scale-up PMTCT interventions (8).

\section{METHODS FOR PROJECT DEVELOPMENT AND EVALUATION}

\section{Project Overview}

PATH, an international non-profit health organization, partnered with Ukrainian nongovernmental organizations (NGOs) 
Table 1. Use of intervention activities to address project objectives

\begin{tabular}{|c|c|c|c|}
\hline \multirow[b]{2}{*}{ Objective } & \multicolumn{3}{|c|}{ Intervention activity } \\
\hline & PATH provider training & $\begin{array}{l}\text { Materials for pregnant } \\
\text { women, mothers, and } \\
\text { families }\end{array}$ & $\begin{array}{l}\text { Peer-support pro- } \\
\text { grammes for newly } \\
\text { diagnosed HIV-positive } \\
\text { pregnant women }\end{array}$ \\
\hline Objective 1: Improve quality of PMTCT services & $\checkmark$ & & \\
\hline Objective 2: Increase access to information by women and families & $\checkmark$ & $\checkmark$ & $\checkmark$ \\
\hline Objective 3: Increase use of PMTCT services by pregnant women & $\checkmark$ & $\checkmark$ & \\
\hline $\begin{array}{l}\text { Objective 4: Increase access to and use of support groups for HIV-positive } \\
\text { pregnant women and mothers }\end{array}$ & $\checkmark$ & & $\checkmark$ \\
\hline Objective 5: Improve facility capacity to integrate PMTCT services & $\checkmark$ & & \\
\hline
\end{tabular}

and government health facilities to increase access to and quality of PMTCT interventions from October 2004 to September 2007. The effort focused on strengthening the quality of information, counseling, and referrals that pregnant women receive and on addressing factors contributing to HIV-related stigma (provider knowledge, skills, and attitudes). The rationale was that improved information dissemination, counseling, and support in clinical facilities and in communities could help pregnant women better understand HIV and risk behaviors, make it more likely that they would access available antenatal care and PMTCT services, and help reduce stigma within health facilities (10-13).

\section{Assessments to Guide Project Development}

To better understand how stigma affected PMTCT and VCT services available to pregnant women, PATH facilitated focus groups with 27 HIV-positive mothers who had given birth within the previous three years. Focus groups took place in April 2005 in Mykolayiv and Sevastopol. Although some focus group participants spoke positively of antenatal care and AIDS Center staff, many women described feeling stigmatized, disregarded, and isolated in the maternity houses: "They admitted me two days before delivery and let me leave through the emergency exit two days after it [delivery], watching me to ensure that I did not touch anything. And right after I left, they washed the ward. When examining me, they put on special masks. They did not let me go out of the hall and make phone calls." All focus group participants believed that confidentiality is violated in medical facilities: "In the registry I was told in public - 'Go and take infant formula. You are HIV-positive after all.' And at the same time, a whole group of people was standing nearby. I felt like turning and running out of there."

Although some women reported positive experiences in pre- and post-test encounters with providers, almost none of the participants had heard of the term "voluntary counseling and testing." Most women felt that one is obliged to know his/her status, but most reported no support throughout the process of testing: "If I had been prepared for the possible results of the test, it would not have been such a nightmare." Almost all women said that no one explained their options regarding HIV testing or what the test involved: "There was no counseling, nobody asked for my consent for testing, and after receiving the results, nobody explained that there was a counselor in the AIDS Center who could explain everything. They just 'showered' me with the results and gave up on me, leaving me alone."

Most women believed that receiving information from people with HIV is one of the most important ways to educate both HIVpositive and HIV-negative people: "There are few counselors working at our AIDS Center. One counselor works for the AIDS Center and visits patients. And the flow of people is very big. A lot of people need help. It is important that not only the infectious disease doctor at an AIDS Center provides counseling but also infected people. I want to talk to someone like me."

The project's baseline assessment also included review of educational materials for maternal and child health personnel and pregnant women and their families. The limited scope of educational and informational materials available to providers and patients, the perceived lack of providers' HIV knowledge and counseling skills, and reports of providers' negative attitudes towards people living with HIV clearly emerged from the baseline data (14).

\section{Intervention Development and Implementation}

The project team developed three interventions: training midwives and obstetrician-gynecologists (ob-gyns); developing behavior change and communication materials for pregnant women and families; and strengthening NGO-based peer support programmes for newly diagnosed HIV-positive women (Table 1). The three interventions were implemented in all six southern Ukrainian cities: Odesa, Mykolayiv, Sevastopol, Simferopol, Yalta, and Feodosiya. These cities were selected as they have some of the highest HIV rates in the country.

Provider training. The provider training aimed to strengthen interpersonal communication and counseling skills of midwives and ob-gyns so that pregnant women would receive high-quality, comprehensive counseling that included HIV-related pre- and posttest counseling and appropriate referrals. It focused on expanding knowledge about HIV, prevention, treatment, and counseling basics; developing and practicing communication and counseling skills; and changing understanding and attitudes of participants towards HIV, people living with HIV, and their role in influencing the HIV epidemic in Ukraine. The interactive teaching methods used by the trainers (role playing, sketches, and working in small groups) were carefully selected to address these three key aspects. Trainings were organized over three consecutive days.

The training promoted interaction among providers as well 
as between providers and women living with HIV. Women with HIV were invited to share their reflections on their experiences as clients in the antenatal clinics and to respond to questions from training participants. This, coupled with providers' personal evaluation of HIV/AIDS-related values, was intended to challenge potential prejudices and stereotypes that the providers may have held.

Educational materials and peer support programmes. The project also engaged local NGOs in activities to improve the quality of VCT services for pregnant women. PATH collaborated with local AIDS service NGOs to develop behavior change and communication materials and a referral system to NGO-based peer support programmes. After careful assessment of existing PMTCT and VCT educational materials, trained staff from local NGOs developed, pretested, and disseminated new materials for maternal and child health providers and pregnant women and their families.

In Odesa and Mykolayiv, PATH's NGO partners developed substantial, working relationships with medical institutions, signing agreements with five antenatal clinics and two maternity homes in Mykolayiv and seven clinics in Odesa. These agreements outlined a system of collaboration and defined a referral system and terms for institutionalizing the referral system in these pilot sites.

\section{Methods for Evaluating Project Outcomes}

The evaluation of provider training sought to answer the following two questions:

1. Did the provider training enhance the provider's ability to offer high-quality information, counseling, and referrals to pregnant women with HIV?

2. Did client perception of the quality of VCT provided at antenatal clinics improve at intervention sites?

A quasi-experimental, non-equivalent control group design was used to evaluate the effect of the provider training intervention. Mykolayiv served as the intervention site, and Sevastopol served as a comparison site. The selection criteria for sites included the number of antenatal care centers, number of providers, population of each city, and degree of centralization of service provision.

Short-term change in provider performance was assessed at two points in time (Table 2). Baseline data were collected for both intervention and comparison groups, and follow-up data were collected one month after the last provider training session was completed at the intervention site. The provider training intervention was subsequently implemented at the comparison site. Evaluation data were collected using two methods: provider observations and client exit interviews.

Provider observation sessions were conducted at all five antenatal care clinics in the intervention site (Mykolayiv) and all six antenatal clinics in the comparison site (Sevastopol). We attempted to observe a census (100 percent sample) of ob-gyns who were working in the antenatal care facilities in the study area. The observer spent one day at each facility to collect data. The team undertook at least one observation per provider on duty on the day when the observer was present in the facility.

A total of 69 providers were observed providing PMTCT counseling (37 in the intervention group and 32 in the comparison group). Both delivery and quality of the overall performance of PMTCT counseling skills were assessed.

Seventeen performance indicators were adapted from other sources and used to evaluate the quality of counseling skills (16). These included five indicators for active listening, six indicators for gathering information, and six indicators for giving information. A summary index of three indicators was used to summarize the overall quality of the counseling.

Clients who were involved in the provider-client observation were invited to participate in exit interviews immediately after counseling sessions. All clients consented to participate in an exit interview. A total of 65 clients participated in the baseline observations and exit interviews ( 35 clients in the intervention group and 30 in the comparison group) and 69 clients participated in the follow-up observations and exit interviews (37 clients in the intervention group and 32 in the comparison group).

For each data set, two analyses were carried out using JMP (SAS Institute, Cary, NC,1994) and SPSS 12.0 for Windows (Chicago, Illinois): (1) an analysis of baseline data to establish comparability between the intervention and comparison sites (not reported here) and (2) an outcomes analysis to assess improvement by comparing responses between the intervention and comparison groups at each time point. Aggregated measures were developed using standard data reduction methods (e.g, factor analysis). The same aggregated measures were used in both the baseline and outcomes analyses. The outcomes analysis included bivariate analyses using $\chi^{2}$ tests to compare associative relationships between the intervention and control groups. Significance levels were set at 0.001 .

At the end of the intervention, three roundtables were conducted in Odesa, Mykolayiv, and Sevastopol with local stakeholders (i.e., health care authorities, officials responsible for VCT in PMTCT and maternal and child care programmes, medical facility representatives, and NGO representatives to discus project results, lessons learned, and challenges they faced over the three-year implementation period. The resulting set of recommendations is included in the discussion section.

Table 2. Timeline for baseline and follow-up data collection at intervention and comparison sites

\begin{tabular}{|l|c|c|c|c|}
\hline \multirow{2}{*}{ Site } & \multicolumn{4}{|c|}{ Project month } \\
\cline { 2 - 5 } & $7-8$ (Mar-Apr 2005) & $\begin{array}{c}\text { 12-17 (Aug 2005- Feb } \\
\text { 2006) }\end{array}$ & 18 (Mar 2006) & $\begin{array}{c}\text { 20-32 (May 2006- May } \\
\text { 2007) }\end{array}$ \\
\hline Intervention site (Mykolayiv) & baseline data collection & intervention conducted & $\begin{array}{c}\text { post-intervention data col- } \\
\text { lection }\end{array}$ & \\
\hline Comparison site (Sevastopol) & baseline data collection & & follow-up data collection & intervention conducted \\
\hline
\end{tabular}


Table 3. Quality of observed interpersonal communication and counseling skills at follow-up among providers in intervention and comparison groups $(n=69)(M \pm S D)$

\begin{tabular}{|c|c|c|}
\hline $\begin{array}{l}\text { Summary indicator for overall counseling process } \\
\text { (Evaluation range: } 0=\text { did not perform; } 3=\text { best) }\end{array}$ & Intervention group ( $\mathrm{n}=37$ ) & Comparison group $(n=32)$ \\
\hline 1. How well did the counselor establish rapport?* & $2.92(0.28)$ & $1.81(0.65)$ \\
\hline $\begin{array}{l}\text { 2. How well did counselor conduct interview using appropriate terminology, body } \\
\text { language, and confidentiality?* }\end{array}$ & $2.54(0.56)$ & $0.56(0.67)$ \\
\hline 3. How well did the counselor conclude the session?* & $2.65(0.72)$ & $1.57(0.63)$ \\
\hline
\end{tabular}

${ }^{*} \mathrm{p}<0.001$

\section{RESULTS}

From August 2005 to February 2006, 14 VCT trainings were held, and 290 doctors and midwives were trained at the intervention site (Mykolayiv).

\section{Provider-client Observation}

Analysis of observation data showed that providers who participated in the training intervention delivered counseling of consistently higher quality than did providers who did not take the training. A significant difference $(p<0.001)$ was observed between the intervention and comparison groups for 15 out of the 17 performance indicators in the interpersonal counseling skills index. Evaluation of a three-indicator summary index showed a strong difference $(p<0.001)$ between the two groups in the quality of the overall counseling process (Table 3 ).

Of the 37 providers in the intervention group, more than half explained mother-to-child transmission risks and interventions $(p<0.001)$ and about three-fourths described the HIV test $(p<0.001)$. By contrast, no provider in the comparison group was observed using these skills. No provider in either group helped the client prepare a risk-reduction plan, and only one provider in the intervention group assessed client risk. The quality of the specific PMTCT counseling actions was also significantly different between the groups in two of four performance areas: explanation of mother-to-child transmission risks and interventions ( $p<0.001)$ and describing the HIV test $(p<0.001)$. There were no differences in the other two performance areas (assessment of risk and assistance in reducing risk).

\section{Client Exit Interviews}

Exit interview data support results from provider observations. Overall, the provision of a complete counseling experience was verified significantly more often by clients in the intervention group than in the comparison group (Table 4). In particular, more clients who had been counseled by PATH-trained providers reported that the counselor had assured them that HIV testing is a voluntary procedure and that their test results were confidential.

Outcome data from the provider-client observations and client exit interviews suggest that the provider training effectively changed provider behavior and client perception of their experience with VCT in antenatal care clinics. Positive effects of the provider training were confirmed in the feedback from project supervisors, stakeholders, and counterparts.

\section{DISCUSSION}

The previously described activities were part of a larger effort to strengthen local and national capacity for the provider training component. In May 2006, PATH organized a working group meeting of national and international experts to discuss the VCT training curriculum for ob-gyns and midwives. As a result of this meeting, PATH made final edits to the manual.

The training program for ob-gyns and midwives now fully corresponds with the national VCT protocol. In September 2007, the Ministry of Health's Department of Education approved the incorporation of the training agenda into the national PMTCT programme for post-graduate education of ob-gyns.

Table 4. Client assessment of counseling experience in intervention and comparison groups at follow-up ( $n=69)$

\begin{tabular}{|c|c|c|}
\hline Aspect of experience & Intervention group $(n=37) n(\%)$ & Comparison group $(n=32) n(\%)$ \\
\hline Discussed personal risk-reduction plan* & $21(56.76 \%)$ & $4(12.50 \%)$ \\
\hline The counselor has assured you that HIV test is voluntary procedure* & $31(83.78 \%)$ & $14(43.75 \%)$ \\
\hline The counselor has assured you that your test results are confidential ${ }^{\star \star}$ & $32(86.49 \%)$ & $16(50.00 \%)$ \\
\hline Agree to be tested & $35(94.59 \%)$ & $25(78.13 \%)$ \\
\hline Are clear about when and where to go to get your test results & $31(83.78 \%)$ & $19(59.38 \%)$ \\
\hline \multirow[t]{2}{*}{ Received enough information on support services if needed } & $19(51.35 \%)$ & $8(25.00 \%)$ \\
\hline & \multicolumn{2}{|c|}{ Mean \pm SD } \\
\hline Complete counselling experience index* (range $0-6$ ) & $4.57(1.72)$ & $2.69(1.67)$ \\
\hline Personal risk assessment and reduction index (range 0-2) & $1.30(0.81)$ & $0.53(0.67)$ \\
\hline
\end{tabular}


Despite this approval, the programme still lacks methodological and regulatory oversight and follow-up support to facilitate full-scale, national implementation. The main barrier is the lack of measures to support an overall supervision system. The following challenges related to introducing a VCT supervision system were identified during project implementation:

- There is no education for supervisors within antenatal care clinics and maternity homes and low awareness among appointed supervisors that VCT supervision is important.

- Supervision responsibility is not included in one's formal job description and is viewed by many supervisors as voluntary work, which reduces motivation.

- Additional trainings and refresher courses for counselors and a feedback system for clients are not budgeted for.

Project results have also led to the following, more specific recommendations for continued improvement in Ukraine's PMTCT programme, especially related to strengthening HIV testing within antenatal services and increasing linkages between health facilities and local NGOs:

- Adjust curriculum to include content on quality assurance. Providers still report that the lack of measures and specified models of quality assurance are major barriers to institutionalizing VCT in Ukraine. Lack of clear reporting forms and a formal supervision system will result in poor performance over time.

- Encourage the Ministry of Health to include VCT supervision responsibilities in job descriptions for appropriate personnel. One of the most critical problems reported by project partners is that VCT supervision is not included in the scope of work (i.e., job description) of health care staff.

- Encourage the Ministry of Health to adopt and formally institutionalize the VCT provider training curriculum into the pre-diploma and post-diploma training programmes of all ob-gyns and midwives. Although this is already accomplished in some professional medical programmes, the goal is for all programmes to integrate the VCT provider training.

- Conduct regular follow-up VCT training. Because counseling and development of psychological support skills are not currently included in most professional medical education curricula at the university or college level, post-training follow-up of VCT is critical for maintaining adequate knowledge and skills. Providers in the pilot cities also recommend extending this medical professional training to their colleagues working in rural areas.

- Extend VCT training to pediatricians, who are responsible for offering HIV testing of infants, to strengthen HIV-related continuum of care. PATH's partners request that similar training and assistance be extended to pediatricians. In addition, HIVrelated stigma among pediatricians needs to be addressed.

- Increase availability of training and informational materials on secondary prevention, and in particular, on family planning, specific to HIV-positive women. Providers requested advice on where to obtain donated supplies, such as condoms, for HIV-positive women. Providers also requested additional training and educational materials on family planning for HIV-positive women.

- Involve experienced NGO counselors in conducting PMTCT psychosocial support trainings. With PATH's technical support, local NGOs were able to build their capacity to develop appropriate and effective trainings in counseling skills and improve collaboration with governmental and NGO partners.

\section{CONCLUSIONS}

In Ukraine, as in many other resource-limited countries, access to and quality of VCT is affected by numerous service delivery gaps. For example, resources to assure quality of VCT are not sufficient, providers are not adequately trained in VCT, and stigma inhibits the provision of appropriate and effective HIV-related support services. This project demonstrated that targeted provider training and assistance to local NGOs can improve VCT quality while addressing the underlying factors contributing to stigma, discrimination, and human rights abuses.

\section{Acknowledgments}

This project was funded through the United States Agency for International Development (USAID) under grant No. 121-G-00-04-00717-00. The opinions expressed herein are those of the authors and do not necessarily reflect the views of USAID.

\section{REFERENCES}

1. UNAIDS. Joint United Nations Programme on HIV/AIDS. Report on the global HIV/AIDS epidemic 2008. Geneva: UNAIDS; 2008.

2. Hamers FF, Downs AM. HIV in central and eastern Europe. Lancet. 2003 Mar 22;361(9362):1035-44.

3. Barcal K, Schumacher JE, Dumchev K, Moroz LV. A situational picture of HIV/AIDS and injection drug use in Vinnitsya, Ukraine. Harm Reduct J. 2005 Sep 15;2(1):16.

4. European Collaborative Study. The mother-to-child transmission epidemic in Europe: evolving in the East and established in the West. AIDS. 2006 Jun 26;20(10):1419-27.

5. World Health Organization; UNAIDS; UNICEF. Epidemiological fact sheet on HIV and AIDS: Ukraine, 2008 Update. Geneva: WHO; 2008.

6. Eastern Europe and Central Asia. In: UNAIDS. AIDS epidemic update: special report on HIV/AIDS. Geneva: UNAIDS,WHO; 2006. p. 37-43.

7. United Nations Children's Fund. Ministry of Health and UNICEF launch new training programme to support HIV-positive children [press release] Kyiv: UNICEF; 20 Mar 2007.

8. Malyuta R, Newell ML, Ostergren M, Thorne C, Zhilka N. Prevention of mother-to-child transmission of HIV infection: Ukraine experience to date. Eur J Public Health. 2006 Apr;16(2):123-7.

9. Human Rights Watch. Rhetoric and risk: human rights abuses impeding Ukraine's fight against HIV/AIDS. New York: Human Rights Watch; 2006 Mar; 18(2)(D).

10. Aggleton P, Parker R, Maluwa M, editors. A conceptual framework and basis for action: HIV/AIDS stigma and discrimination. World AIDS Campaign, 2002-2003. Geneva: UNAIDS; 2002.

11. Alonzo AA, Reynolds NR. Stigma, HIV and AIDS: an exploration and elaboration of a stigma trajectory. Soc Sci Med. 1995 Aug;41(3):30315 .

12. Oberzaucher N, Baggaley R. HIV voluntary counseling and testing: a gateway to prevention and care. Geneva: UNAIDS; 2002.

13. UNDP/UNFPA/WHO/World Bank Special Programme of Research, Development and Research Training in Human Reproduction. HIVinfected women and their families: psychosocial support and related issues: a literature review. WHO/RHR/2003/07. Geneva: Department of Reproductive Health and Research WHO, 2003.

14. PATH. Integrating PMTCT of HIV into MCH services in Ukraine [unpublished report]. Kyiv: December 2005.

15. Joint United National Programme on HIV/AIDS. Tools for evaluating HIV voluntary counseling and testing. Geneva: UNAIDS; 2000.

Received February 15, 2008 Accepted in revised form February 9, 2009 